Published in final edited form as:

Curr Top Microbiol Immunol. 2009 ; 333: 369-393. doi:10.1007/978-3-540-92165-3_18.

\title{
Microneedle-based vaccines
}

\author{
Mark R. Prausnitz, \\ School of Chemical and Biomolecular Engineering, Georgia Institute of Technology, 311 Ferst Drive, \\ Atlanta, GA 30332-0100, Ph: (404) 894-5135, Fax: (404) 894-2291, prausnitz@gatech.edu \\ John A. Mikszta, \\ BD Technologies, 21 Davis Drive, Research Triangle Park, NC 27709, Ph: (919) 597-6158, Fax: \\ (919) 597-6402, john_mikszta@bd.com
}

Michel Cormier, and

278 Andsbury Avenue, Mountain View, CA 94043, michel.cormier@sbcglobal.net

\section{Alexander K. Andrianov}

Apogee Technology, 129 Morgan Drive, Norwood, MA 02062, Ph: (781) 551-9450, Fax: (781)

440-9528, aandrianov@apogeemems.com

\section{Abstract}

The threat of pandemic influenza and other public health needs motivates development of better vaccine delivery systems. To address this need, microneedles have been developed as micron-scale needles fabricated using low-cost manufacturing methods that administer vaccine into the skin using a simple device that may be suitable for self-administration. Delivery using solid or hollow microneedles can be accomplished by (i) piercing the skin and then applying a vaccine formulation or patch onto the permeabilized skin, (ii) coating or encapsulating vaccine onto or within microneedles for rapid, or delayed, dissolution and release in the skin and (iii) injection into the skin using a modified syringe or pump. Extensive clinical experience with smallpox, TB and other vaccines has shown that vaccine delivery into the skin using conventional intradermal injection is generally safe and effective and often elicits the same immune responses at lower doses compared to intramuscular injection. Animal experiments using microneedles have shown similar benefits.

Microneedles have been used to deliver whole, inactivated virus; trivalent split antigen vaccines; and DNA plasmid encoding the influenza hemagglutinin to rodents and found strong antibody responses. In addition, ChimeriVax ${ }^{\mathrm{TM}}-\mathrm{JE}$ against yellow fever was administered to non-human primates and generated protective levels of neutralizing antibodies more than seven times greater than subcutaneous delivery; DNA plasmid encoding hepatitis B surface antigen was administered to mice and generated antibody and $\mathrm{T}$ cell responses at least as strong as hypodermic injections; recombinant Protective Antigen of Baccilus anthracis was administered to rabbits and provided complete protection from lethal aerosol anthrax spore challenge at a lower dose than intramuscular injection; and DNA plasmid encoding four vaccinia virus genes administered to mice in combination with electroporation generated neutralizing antibodies that apparently included both Th1 and Th2 responses. Dose sparing with microneedles was specifically studied in mice with the model vaccine ovalbumin. At low dose $(1 \mu \mathrm{g})$, specific antibody titers from microneedles were one order of magnitude greater than subcutaneous injection and two orders of magnitude greater than intramuscular injection. At higher doses, antibody responses increased for all delivery methods. At the highest levels $(20-80 \mu \mathrm{g})$, the route of administration had no significant effect on the immune response. Concerning safety, no infections or other serious adverse events have been observed in well over 1000 microneedle insertions in human and animal subjects. Bleeding generally does not occur for short microneedles $(<1 \mathrm{~mm})$. Highly localized, mild and transient erythema is often observed. Microneedle pain has been reported as non-existent to mild, and always much less than a hypodermic needle control. Overall, these studies suggest that microneedles may provide a safe and 
effective method to deliver vaccines with possible added attributes of requiring lower vaccines doses, permitting low-cost manufacturing, and enabling simple distribution and administration.

\section{Introduction}

The threat of a human influenza pandemic has greatly increased over recent years with the emergence of highly virulent avian influenza viruses [26]. Influenza experts agree that another influenza pandemic is inevitable and maybe imminent [90]. Vaccines are a critical component of pandemic influenza preparedness, yet the development and supply of such vaccines can be limited by a number of challenges, including inadequate production capabilities [90].

Preliminary findings have identified the $\mathrm{H} 2, \mathrm{H} 5, \mathrm{H} 6, \mathrm{H} 7$, and $\mathrm{H} 9$ subtypes of influenza A as those most likely transmitted to humans [90]. The current widespread circulation of H5N1 viruses among avian populations creates an unprecedented opportunity to prepare for the next pandemic threat. However, the major difficulty in the development of effective vaccines based on these viruses stems from the fact that, for unknown reasons, hemagglutinin (HA) proteins of avian subtypes of influenza A viruses are not as immunogenic as those of human subtypes. Thus, to achieve the protective level of immunity, the amount of HA in pandemic vaccines needs to be increased and is likely to exceed the $15 \mu \mathrm{g}$ present in the currently used interpandemic vaccines [83]. Such an increase in the dose will put additional strain on the manufacturing capacity, potentially leading to a decrease in availability of vaccine in the event of pandemic.

The need for developing technologies, which would result in the reduction of the antigen dose required to elicit protective antibody titers, is evident. Exploration of such dose sparing technologies includes the development of effective adjuvants and the use of alternative routes of vaccine administration, such as intradermal. Intradermal injection of influenza vaccine could be a highly desirable antigen-sparing strategy. Conventional injection of vaccine bypasses the skin's immune system and delivers the antigen into the muscle or sub-cutaneous tissue, where there is no appreciable resident population of antigen-presenting cells. Alternatively, delivery of antigen to the skin, an anatomic space that contains a large number of epidermal Langerhans cells and dermal dendritic cells has the potential for greater immunogenicity. Dendritic cells are thought to induce cell-mediated immune responses. However, they have also been shown to enhance antibody production by B cells, which is especially important for vaccines against influenza [43]. Recent studies in young adults demonstrated that intradermal administration of one fifth the standard intramuscular dose of influenza vaccine elicited immunogenicity that was similar to or better than that elicited by intramuscular injection $[9,42]$.

Intradermal immunization, though, is facing technical challenges that must be addressed in order to effectively administer such vaccines. The approach requires either special training of personnel [43], which can be difficult to achieve in clinical environments, or the development of technologies that do not involve the use of conventional needles. To overcome the stratum corneum barrier and increase skin permeability, various alternative approaches have been explored, which include both chemical and physical techniques.

The use of microneedles, sub-millimeter structures designed to pierce the skin and deliver vaccines or drugs in the epidermis or dermis compartments, is an especially attractive option for intradermal delivery [73]. Such microneedles are typically constructed as a combination of vaccine or drug formulation with a supporting material, such as metal or polymer, providing the required mechanical strength. Solid state vaccine formulations can be in the form of coatings or they may even constitute the entire microneedle. These formulations are designed to dissolve or degrade once inserted in the skin. An alternative approach utilizes hollow microneedles through which the liquid formulation can be infused or injected into the skin. 
Regardless of the design, the geometry of microneedles is modulated to enable targeted delivery of the antigen to the skin layer, rich in Langerhans cells, and to provide the basis for a significant antigen sparing potential.

The advancement of microneedles for the delivery of vaccines against pandemic influenza can include other important benefits. First, the use of microneedles containing solid state vaccine delivery formulations can result in a significantly improved shelf-life of such delivery systems due to the inherently better stability of solid state protein formulations compared to their conventional solution counterparts. As a result, more efficient distributions and stock-piling capabilities, much needed for vaccines against pandemic influenza, are anticipated. Second, microneedle arrays can potentially be self-administered and safely disposed of, which can be critical in the event of shortage of medical personnel.

The current status of microneedle technology, as well as its potential role in the development of effective vaccines against pandemic influenza, is discussed in this chapter.

\section{Microneedle designs and delivery concepts}

Four different microneedle designs have been developed for minimally invasive delivery of vaccines and other pharmaceutical compounds to the skin, as discussed in previous review articles $[12,17,19,55,71-75,77,81]$. Most microneedle designs have been realized using fabrication tools adapted from the microelectronics industry or other established techniques that lend themselves to inexpensive mass production as a single-use, disposable device. Microneedle materials are generally metals and polymers that are already FDA-approved for implantation or parenteral delivery for other applications.

The first design developed involves arrays of hundreds of microneedles protruding a few hundred microns from a base substrate that have been used either to pierce or to scrape microscopic holes in the skin's outer layer of stratum corneum, which measures just $10-20$ $\mu \mathrm{m}$ thick, but provides the skin's dominant barrier to percutaneous absorption (Fig. 1) [13, 76]. By piercing the skin, transdermal permeability has been increased by as much as four orders of magnitude and shown to deliver compounds including proteins (e.g., bovine serum albumin), genetic material (e.g., oligonucleotides and plasmid DNA) and latex particles of viral dimensions in vitro and in vivo $\left[11,15,20,35,{ }^{48}, 51,56,67,69,85,87,95,96\right]$. By scraping the skin, protein (e.g., the recombinant Protective Antigen of Bacillus anthracis), plasmid DNA (e.g., encoding hepatits B surface antigen) and live attenuated virus (e.g., viral vector encoding Japanese encephalitis antigens) vaccines have been delivered to animal models, as discussed below $[23,57,59]$. These methods make micron-scale holes in the skin, which are much larger than the size of sub-unit as well as viral vaccines, but should nonetheless be small enough to avoid safety concerns, which is consistent with the lack of pain or complications observed in studies of human subjects and animals [28,32,41,57].

Solid microneedles can also be prepared with dry vaccine coatings (Fig. 2). These coatings can be applied using gentle conditions at room temperature with aqueous solvents and excipients approved for parenteral delivery [29,30]. Although shown to be stable during storage for up to months, these coatings can dissolve off microneedles within the skin on a time scale of seconds. Using this approach, various model compounds, including proteins, DNA and viruses, have been coated and delivered to the skin in vitro; a model vaccine, ovalbumin (OVA), has also been delivered to animals in vivo, as discussed below [18,29-31,37,54,80,92,97].

In contrast to coated microneedles, which apply a vaccine-encapsulated polymer coating onto a metal microneedle shaft, microneedles have also been prepared completely out of polymer with encapsulated vaccine (Fig. 3). By optimizing design, these polymer microneedles can be made strong enough to insert into the skin. By using polymers that safely degrade or dissolve 
in the skin, microneedles can be inserted into the skin and left in place for a few minutes, after which the needles and their vaccine payload have dissolved in the skin and only the device backing remains to be discarded (i.e., without biohazardous sharps). Loadings have been demonstrated up to $2 \mu \mathrm{g}$ per microneedle with dissolution efficiencies up to more than $90 \%$ dissolved within the skin and little residue on the skin's surface [29,92]. This concept has been demonstrated in vitro and in vivo for delivery of insulin, erythropoietin and other model compounds $[39,40,47,60,68,84]$.

A final approach to vaccine delivery involves hollow microneedles (Fig. 4). In this case, one or more hollow needles are used to flow a liquid formulation into the skin. Sub-millimeter needles have been fabricated using microfabrication techniques and 30 to 34 gauge $(\mathrm{Ga})$ hypodermic needles measuring 1.0 to $1.5 \mathrm{~mm}$ in length have been produced by scaling down conventional needle manufacturing methods. A recent study examining skin thickness in humans has shown that a skin penetration depth of $1.5 \mathrm{~mm}$ is appropriate for intradermal delivery irrespective of gender, age, ethnicity or body mass index [45]. Hollow microneedles have been shown to infuse or inject a variety of compounds, including insulin, into the skin in vitro, in animals and in humans, and have been used to deliver influenza and anthrax vaccines to animal models, as discussed below $[4,22,23,28,52,53,56,58,59,65,82,85,89]$.

Selection of the best microneedle design depends on the specific application and a balance of trade offs. Hollow microneedles offer the ability to deliver liquid vaccines without reformulation, but involve the added cost and size of coupling with an injection device (e.g., a syringe), the potential need for trained personnel for administration, and the need to either stabilize a liquid formulation during storage or the need to reconstitute the vaccine before injection. Coated microneedles can be prepared as a Band Aid-sized device that can probably be administered with little or no training using a solid formulation that may have good stability during storage, but require specific vaccine formulation work and may require a device for reliable insertion into the skin. Encapsulated polymer microneedles have similar trade offs, with the added advantage of using needles that dissolve in the skin without producing medical sharps waste. Finally, pretreating the skin with microneedles before applying, for example, a vaccine patch, while simple in principal, is associated with a potential risk of user error due to the two-step process.

\section{Vaccination via the skin}

Microneedles are designed to facilitate intradermal delivery of vaccines, which is generally difficult to perform in a highly reproducible way in large populations. The notion of administering vaccines via the skin has existed for many centuries. The ancient Chinese practiced the art later known as "variolation" in which variola virus (smallpox virus) extracted from infected patients was scratched into the skin of healthy people [25]. The intent was to deliberately induce smallpox infection, hopefully mild, which would protect against potentially more severe natural infection. While effective in many cases, the practice was associated with significant mortality. Later, the term "vaccination" was coined as a result of Edward Jenner's demonstration that scratching the related but less virulent vaccinia virus (cowpox virus) into the skin could effectively prevent smallpox virus infection [25]. Even today, smallpox vaccination is accomplished by administering vaccinia virus to the skin using a bifurcated needle. What was not known by the ancient Chinese or by Edward Jenner and his followers is the fact that the skin is a very robust immune activating tissue due, in part, to the large concentration of potent antigen-presenting cells in the skin, notably the epidermal Langerhans cells and dermal dendritic cells [38,44].

In addition to smallpox, a number of other vaccines have been administered to the skin using conventional needles and syringes according to the so-called "Mantoux technique" [91]. This 
method is accomplished by inserting a standard 26 or 27 Ga needle into the skin at a very shallow angle with the bevel up. The needle is very carefully inserted just far enough into the skin to completely cover the bevel and then $0.1 \mathrm{ml}$ of fluid is injected into the skin, resulting in formation of a raised wheal. This technique requires extensive training and is difficult to accomplish reproducibly. Furthermore, it is extremely difficult to precisely control the injection depth with this technique since the needle is inserted at an angle that is determined by the user; injections that are too deep deposit the vaccine into the subcutaneous (SC) tissue under the skin, while injections that are too shallow result in leakage of part of the dose out of the skin during the injection or after the needle is removed.

To address the limited control and reproducibility of these existing methods of vaccine delivery to the skin, microneedle-based delivery has been developed to provide a means to more accurately and reproducibly access the skin in a less invasive fashion compared to what is possible using standard needles and the Mantoux technique. This feature could result in skin becoming the preferred site for administration of a variety of vaccines.

\subsection{Influenza vaccine}

Over the years, clinicians have used the Mantoux method for intradermal (ID) delivery of influenza vaccine and have shown this route to be effective [7,10,14,16,34,36,42]. Some studies have suggested that ID delivery of a low dose of influenza vaccine induces comparable levels of antibody as standard intramuscular (IM) injection of up to 5 times more antigen[9, 42]. In a recent follow-up study, however, Belshe et al. did not observe such dose-sparing benefits associated with delivery by the Mantoux method [10]. Studies are on-going in order to determine whether microneedles may provide more reproducible benefits for ID delivery. Recent clinical results in elderly subjects support the notion that ID delivery using microneedles induces a superior immune response as compared to IM [46].

Pre-clinical studies have also supported the notion that microneedles can provide benefits over standard IM injection for influenza vaccine. A recent study examined delivery of various types of influenza vaccines using a $1 \mathrm{~mm}$ long stainless steel hollow $34 \mathrm{Ga}$ microneedle in rodents (Fig. 5) [4]. Microneedle-based ID delivery was compared to IM injection using a conventional $27 \mathrm{Ga}$ needle. Three types of influenza vaccines were examined: (i) whole, inactivated virus, (ii) trivalent split antigen vaccine and (iii) a DNA plasmid encoding the influenza hemagglutinin (HA). In addition, both high and low dose regimens were included for both routes of delivery and for each vaccine. The results demonstrated that microneedle-based ID delivery induces influenza-specific antibody responses that are at least as strong as by IM injection (Fig. 5) [4]. Dose-sparing was also evident; in many cases antibody responses induced by microneedle delivery remained elevated, while the corresponding responses elicited by IM injection dropped as the dose was reduced (Fig. 5) [4] Importantly, recent clinical trials have shown that microneedle-based ID delivery of influenza vaccine induces stronger humoral immune responses in the elderly as compared to IM injection [46].

Additional studies carried out in the hairless guinea pig have demonstrated that microneedlecoated trivalent influenza vaccine can induce primary anti-HA antibody responses to each strain comparable to their respective intramuscular injection controls [50]. No significant difference, with respect to antibody responses, was seen among the various microneedle array designs used, which seems to at least partially confirm the results obtained with OVA. It also suggests that the length of the microneedles, in the range $225-600 \mu \mathrm{m}$, does not play an important role in the establishment of a solid immune response [92]. 


\subsection{Other vaccines}

As noted above, smallpox vaccine has historically been administered to the skin by scarification using a bifurcated needle. Despite the general effectiveness of the approach, the use of live vaccinia virus makes the vaccine unsuitable for many populations (e.g., infants, pregnant women, immune-compromised / immune-suppressed individuals). In addition, vaccination often results in a severe skin reaction and a permanent "pock-mark" on the skin. Various investigators are exploring alternative vaccines and delivery methods in order to overcome these issues [70,93]. Hooper et al. recently described an approach using a solid microneedle array incorporated into a device for skin electroporation [37]. The microneedle array was coated with dried plasmid DNA encoding four vaccinia virus genes and applied to mouse skin, followed by electroporation. Mice generated a neutralizing antibody response that was at least as strong as by scarification and were protected from a lethal nasal challenge with vaccinia virus. Furthermore, both IgG1 and IgG2a antibodies were induced by this method of delivery, suggesting the induction of both Th1 and Th2 responses [37].

The method of puncturing live virus into the skin by scarification has also been historically used with yellow fever viruses [62]. More recently, microneedles have been used to administer a live, attenuated yellow fever virus vector in non-human primates [23]. The vaccine, ChimeriVax ${ }^{\mathrm{TM}}-\mathrm{JE}$, contains the yellow fever 17D strain genetically engineered to encode structural proteins of the related Japanese encephalitis (JE) virus [63]. Successful delivery is associated with a low level of transient viremia resulting from uptake of the virus by host antigen-presenting cells. Delivery by both hollow and solid microneedles induced viremia that, in general, was of a higher frequency and duration than by SC injection using a standard needle (Table 1) [23]. Notably, protective levels of neutralizing antibodies were detected in animals treated by all routes, with microneedle-based delivery inducing responses that were up to 7 fold greater than by SC injection using conventional needles [23]. Interestingly, viremia resulting from delivery by scraping a solid microneedle array across the skin varied according to the method of delivery; 1 of 3 macaques became viremic when skin was pre-treated with the array followed by topical application of the virus, while 3 of 3 macaques became viremic when the array was abraded through the droplet of vaccine on the surface of the skin. Additional studies are required in order to determine the mechanism for these differences as well as the clinical significance of the result.

Plasmid DNA has also been administered to mice using solid microneedle arrays following the procedure whereby the array is rubbed across a droplet of vaccine on the surface of the skin. Mice treated with a plasmid encoding the Hepatitis B surface antigen ( $\mathrm{HBsAg}$ ) generated antibody and $\mathrm{T}$ cell responses that were as strong or stronger than by injection using standard needles [57]. In addition, both IgG1 and IgG2a subclasses of antibody were induced, suggesting a mixed and balanced helper $\mathrm{T}$ cell response from this method of delivery.

Protein antigens have also been administered using microneedles. In a rabbit study, various routes of delivery were compared for the recombinant Protective Antigen (rPA) of Bacillus anthracis [59]. Rabbits immunized intradermally using hollow microneedles were completely protected from a lethal aerosol anthrax spore challenge, as were animals treated by the IM and intranasal (IN) routes. Although topical delivery to the skin following pretreatment with a solid microneedle array induced antibodies at levels above those in animals treated topically without the device, only $33 \%$ protection was achieved. These results suggest that further improvements in the delivery method and/or the topical formulation will be required in order for this method to be comparable to injection for protein vaccines. In follow-up studies using the hollow microneedle, it was shown that $100 \%$ protection against lethal aerosol spore challenge could be achieved using as little as $10 \mu \mathrm{g}$ of rPA, while IM-injection of the same dose protected approximately $70 \%$ of rabbits [58]. Dose-sparing compared to IM injection was also evident during the early stages of the primary and secondary immune responses. 
OVA has also been used as a model protein antigen for microneedle-based delivery. In this study, OVA was coated on the surface of solid microneedles and allowed to dissolve off the microneedles within the skin of hairless guinea pigs (HGP) [54,92]. As discussed in greater detail in the next section, antibody responses generated by delivery using microneedles were at least as strong as intradermal, subcutaneous and intramuscular delivery using conventional hypodermic needles.

More specifically, the immune response was found to be dose dependent, but mostly independent of depth of delivery (100 to $300 \mu \mathrm{m})$, density of microneedles ( $140-725$ needles/ $\left.\mathrm{cm}^{2}\right)$, or area of application $\left(2-4 \mathrm{~cm}^{2}\right)$ [92]. It is surprising that the microneedle length did not have a dramatic effect on the immune outcome. The skin is highly stratified, with the highest abundance of dendritic cells, critical for antigen uptake and initiation of antigen-specific immune responses, located predominantly along the dermal-epidermal junction. On another hand, it is well known that the dermis is also rich in other dendritic antigen presenting cells [64] and, in light of the results discussed here, it is likely that these cells also play a crucial role in the establishment of a solid immune response. With respect to the area of application and the density of microneedles, only minor differences were observed, which seems to indicate that here too the total dose is the most crucial parameter to establish the antibody response [92].

\section{Dose sparing}

A number of studies mentioned above indicate that microneedle-based delivery to the skin can generate the same immune response as delivery using higher vaccine doses via other routes. This dose-sparing ability was specifically studied using an antigen-coated microneedle array in the HGP model using the model antigen OVA [54,92]. The HGP is outbred, euthymic, and has been used in vaccine $[49,79]$ and contact sensitization studies [61,94]. The following parameters were investigated: route of administration, dose of vaccine delivered, depth of vaccine delivery, density of microneedles on the array, and area of application.

The first set of studies (Fig. 6) used microneedles penetrating the skin to an average depth of about $100 \mu \mathrm{m}$, which correspond to the thickness of the epidermis and very upper dermis layers. In these studies, which compared different routes of administration, it was found that at low dose of antigen delivered $(1 \mu \mathrm{g})$, the immune response, as measured by specific antibody titers, was most efficient following microneedle and ID administration as compared to SC or IM administration. The immune response was more than one order of magnitude higher following microneedle-based administration versus SC delivery, and about two orders of magnitude greater as compared to IM delivery.

The immune response increased with increasing dose (in the range of 1 to $80 \mu \mathrm{g}$ administered antigen) for all routes of administration. This increase was most pronounced with the SC and IM routes of administration. As a result, at the highest doses studied (i.e. 20 and $80 \mu \mathrm{g}$ ), there were no significant differences between the different routes of administration, demonstrating that microneedles and ID delivery had a dose sparing effect, but did not further increase the immune response at high antigen doses. This may be the result of an upper limitation of the immune response with increasing doses as has been observed with other antigens [5,24]. Indeed it is well known that, from an antibody response standpoint, there is little benefit in increasing the dose of antigen above certain thresholds.

Dose-sparing potential was further demonstrated by incorporation of the model adjuvant glucosaminylmuramyl dipeptide (GMDP) into the OVA coating, which produced a significant dose sparing effect following co-administration of $1 \mu \mathrm{g}$ antigen [54]. At this dose, the antibody titer generated with microneedles that co-delivered OVA and GMDP approached the titer levels achieved with OVA doses of $20 \mu \mathrm{g}$ in the absence of GMDP, which demonstrates a significant 
dose-sparing effect and indicates that the technology is amenable to the co-delivery of antigen and adjuvant.

\section{Safety}

Microneedles are minimally invasive delivery systems that have been designed for safety. Safety concerns are chiefly related to the risk of infection. Other factors to consider, linked mostly to user acceptability and environmental issues, include pain, local bleeding, skin irritation, and residual vaccine left in the system and on the skin surface.

\subsection{Infection}

Based on experience with hypodermic needles, the greatest risk of infection comes from the use of contaminated needles [6]. Thus, single-use microneedles that are sufficiently clean (e.g., sterilized) should pose little threat of infection. However, the skin is constantly in contact with environmental organisms and becomes readily colonized by certain microbial species [78]. Most skin microorganisms, found in the most superficial layers of the epidermis and the upper parts of the hair follicles, are nonpathogenic, but sometimes potentially pathogenic species such as Staphylococcus aureus and Streptococcus pyogenes can be found on the skin.

Any breach in the skin can be a door of entry for microorganisms that could cause local or even systemic infection. Microneedle arrays containing up to hundreds and possibly thousands of microneedles could therefore be problematic. However, the risk of infection is related to a large number of factors including the size and number of the breaches, the depth of the breaches, the number of microorganisms entering the skin and their nature, and the individual susceptibility of the patient. In clinical practice, it seems unlikely that the small shallow injuries resulting from the use of microneedles would result in significant safety concerns. Indeed, the skin barrier is routinely breached during common experiences of minor abrasion, such as shaving, yet infection rarely occurs.

There are several preclinical and clinical studies that indicate that the risk of infection resulting from microneedle administration is minimal $[17,18,54,92]$ In the animal studies discussed above, that were in some cases conducted with non-sterile systems, there were no signs of infection reported. It is noteworthy that these animals were carefully monitored typically for many weeks after microneedle treatment under the careful supervision of veterinary staff with IACUC-mandated scrutiny. In addition, microneedle devices have been inserted into the skin well over 1,000 times in more than 100 human subjects through the collective experience of the authors. In these human studies, there have been no microneedle-related infections and, indeed, no serious adverse events.

It is worth noting that these studies in animals and humans were conducted in healthy subjects and that, prior to application of the microneedle arrays, skin treatment sites were typically cleansed with alcohol wipes to reduce the skin's microbial bioburden $[3,8]$. Therefore, it is unknown what the infection potential would be in widespread use or, for example, in immune compromised patients. As a result of these uncertainties, and depending on the target population and clinical indication, it is possible that the regulatory agencies would require that any future commercial product use a skin cleansing pretreatment procedure as well as a low bioburden or sterile microneedle system.

As additional information, more than 125,000 microneedle devices designed as a cylindrical roller with solid microneedles protruding around the circumference have been sold around the world for cosmetic purposes (http://www.dermaroller.de). These devices are typically applied to the skin either by clinical personnel or by patients themselves, who may re-use them without sterilization or without even washing between uses. Although formal safety data on these 
microneedle rollers do not exist, the manufacturer reports no known adverse events, as long as the microneedles are not re-used (personal communication from Horst Liebl). Altogether, this extensive anecdotal evidence holds promise for the safety of microneedles.

\subsection{Pain}

Although pain is not a safety concern per se, it nonetheless affects patient acceptance and the perception of safety. Initial studies showed that insertion of sharp-tipped microneedles or scraping of blunt-tipped microneedles measuring $50-200 \mu \mathrm{m}$ in length and assembled in arrays of up to 400 microneedles were generally regarded as painless by human subjects [ 41 , 57].

More detailed studies showed that microneedle length correlates strongly with pain, such that an increase in microneedle length from $500 \mu \mathrm{m}$ to $1,500 \mu \mathrm{m}$ (i.e., a three-fold increase in length) resulted in a seven-fold increase in pain score from blinded human subjects [32]. Increasing the number of microneedles from 5 to 50 (i.e., a ten-fold increase) increased the pain score just 2.5 -fold. Varying microneedle width, thickness and tip angle did not have a significant effect on pain. In all cases, the pain score from microneedles was many fold less than the $26 \mathrm{Ga}$ hypodermic needle used as a positive control and for the best microneedle design the pain score was just $1 / 20^{\text {th }}$ that of the hypodermic needle. In another recent study, subject perception associated with insertion of a $1.5 \mathrm{~mm}$ microneedle perpendicularly into the skin was shown to be significantly less than that observed when a standard needle was inserted into skin at a shallow angle [45].

\subsection{Bleeding}

The epidermis is devoid of vasculature and the most superficial capillary bed is located in the upper dermis close to the dermal-epidermal junction [8]. As a result, microneedles penetrating the skin deeper than about $100 \mu \mathrm{m}$ could breach capillaries. Despite this expectation, most animal and human studies have not observed bleeding after microneedle treatment.

In a study examining microneedles to extract interstitial fluid from the skin of hairless rats, microneedles were inserted into the skin hundreds of times to depths of $700 \mu \mathrm{m}$ to $1,500 \mu \mathrm{m}$ [88]. In the absence of suction, no fluid was seen to exude from the skin. With the application of suction, interstitial fluid could be extracted, but this fluid generally appeared clear, without evidence of blood. Similar results were seen in replicate experiments in six human subjects.

In the vaccine delivery experiments discussed above, as well as other experiments involving delivery of various therapeutic and model compounds in animal models including mice, hairless rats, and rhesus macaques, microneedle treatment has generally not been associated with bleeding $[4,22,23,28,51,56-59]$. However, in one study involving hairless guinea pigs [92], $225 \mu \mathrm{m}$ long microneedles were found to penetrate the skin to an average depth of about $150 \mu \mathrm{m}$ and produced at most pinpoint bleeding and $600 \mu \mathrm{m}$ long microneedles were found to penetrate the skin to an average depth of about $300 \mu \mathrm{m}$, well beyond the location of the dermal capillary bed, and produced significant bleeding.

In human subjects, bleeding has also generally not seen for microneedles ranging in size from $500-1000 \mu \mathrm{m}$ [32]. However, $1.5 \mathrm{~mm}$ microneedles have been reported separately to leave a small droplet of blood sometimes on the skin after insertion of solid microneedles [32] and injection using hollow microneedles [8].

\subsection{Skin irritation}

No significant skin irritation (i.e., erythema and edema) has been noted in a number of studies involving insertion of microneedles alone or for delivery of biologics [17,22,28,48,51,54,56]. 
However, experiments in human subjects have shown highly localized spots of redness that corresponds exactly to the sub-millimeter sites of each microneedle insertion [32]. This mild erythema was visible under close inspection, but is unlikely to be of cosmetic concern. In many subjects, it disappeared within minutes and in most subjects within hours. A recent clinical evaluation of a $1.5 \mathrm{~mm}$ length micro-delivery system indicated very minor local effects (e.g., redness, itching) that spontaneously resolved within $20-30$ minutes without any long-term adverse events [45].

Vaccine delivery using microneedles includes the added complexity of local immune response to the vaccine. For example, the average total skin score (combined erythema and edema, maximum combined score of 8 ) for all treatment groups after OVA immunization was just 0.3 at $24 \mathrm{~h}$ following primary immunization, but increased to 2.3 at $24 \mathrm{~h}$ following booster immunization [92]. Although mild and transient, these scores indicated an immune-mediated skin response, possibly a delayed type hypersensitivity response. Skin response following intradermal administration of vaccines has been routinely observed in the clinic [9] and it is likely that they will be also observed following introduction of a vaccine into the skin using microneedles. These responses might cause minor discomfort at the site of application.

\subsection{Microneedle and skin residuals}

The implications of having residual vaccine left on the microneedles or at the surface of the skin depends on the specifics of the vaccine and its formulation. In any case, minimizing residual would be beneficial from a safety and environmental standpoint.

When microneedles are pierced into or scraped across the skin before or in the presence of a topical vaccine formulation, it is likely that a large fraction of the vaccine remains on the skin surface, although this has not been quantified. Following injection using a hollow microneedle, fluid hold up in the syringe may be similar to that during conventional hypodermic injection.

Following application of OVA-coated microneedles to HGP in vivo, a mass balance showed that $12 \%$ of the coated OVA remained on the microneedles, $11.5 \%$ of the total dose was found on the skin surface, and the remaining $76.5 \%$ was assumed to be delivered into the skin [92]. Although the antigen was administered into the uppermost layers of the skin, it was not extraced by extensive cleansing of the skin surface. A study using microneedles coated with vitamin B inserted into cadaver skin found that $91 \%$ of the dose was delivered into the skin, with $7 \%$ remaining on the microneedles and $2 \%$ on the skin surface [29]. This indicates that through proper engineering, contamination issues can be minimized to a considerable extent.

\section{Logistical issues}

In addition to expected increases in vaccine efficacy and safety, the use of microneedles is expected to additionally provide logistical simplifications, which may be especially beneficial for vaccine administration during a pandemic. These simplifications include (i) easier vaccine administration, including the possibility of self administration, (ii) more rapid vaccine distribution and easier stockpiling and disposal and (iii) inexpensive manufacturing costs.

\subsection{Vaccine administration}

Many microneedle designs envision a vaccine patch that would look and be applied similarly to a nicotine patch or a Band Aid. After peeling off a protective release liner to expose the microneedles, the patch is pressed to the skin and perhaps held in place by an adhesive incorporated onto the patch, if needed. Patch placement may be accomplished by hand or may require the use of a small device that presses the patch against the skin with a reproducible force to assure correct microneedle insertion into the skin $[21,98]$. This tool could measure just a few centimeters in size and could be, for example, a disposable, plastic, spring-loaded device. 
After some seconds or minutes, the patch is removed and discarded. Studies carried out in human subjects have shown that microneedles can be inserted into the skin with little or no pain $[32,41,57]$, which suggests that patient compliance can be increased.

Other designs involve hollow microneedles. Notably, a newly described hollow microneedle injection system was shown to be effective for intradermal delivery even in the hands of untrained users [45]. Untrained users were at least as effective as extensively trained users in performing a correct intradermal injection. These results suggest that, with proper engineering, hollow microneedle delivery devices can achieve a high level of user-friendliness.

These simple delivery methods can shift the responsibility of vaccine administration to minimally trained personnel and possibly to patients themselves, leaving doctors and nurses in a supervisory role. This could have major advantages in a pandemic, where a critical bottleneck is assembling huge populations of patients at central locations and having sufficient medical personnel to administer vaccines, or possibly other therapies [26,33]. Allowing minimally trained personnel to administer the vaccines would significantly ease this bottleneck and allowing self administration would increase throughput even more. Simple vaccine administration would also benefit seasonal influenza vaccination (e.g., patients pick up vaccine patches at the pharmacy for self administration at home) and mass vaccination campaigns in the developing world (e.g., polio vaccination campaigns annually administer more than 2 billion doses over the course of a series of intensive 'immunization days,' which is possible only because of the simple delivery method enabled by oral administration of the polio vaccine [2].

\subsection{Vaccine distribution}

Because speed will be critical during a pandemic, manufacturing, stockpiling, distribution and disposal of vaccine delivery systems need to be simplified and expedited. Using microneedles to deliver vaccine can expedite the response to a pandemic because intracutaneous delivery using microneedles is expected to require, perhaps, an order of magnitude less vaccine per dose, as discussed above. Given that production of the vaccine antigen will be a rate-limiting step when responding to an emerging threat, the need to manufacture less vaccine can significantly expedite getting vaccine to the public $[26,33,86]$.

Conventional vaccine delivery systems, which often involve a hypodermic needle, syringe, vial of lyophilized vaccine and vial of diluent, can easily occupy tens of cubic centimeters including their packaging [1]. In contrast, pre-filled microneedle injection devices and, to an even greater extent, microneedle patches are expected to occupy much less space. Some of the thinnest patch-based systems are expected to be much less than one cubic centimeter in size and have a flat profile, which facilitates stacking. Moreover, with improvements in vaccine stabilization technologies, it may be possible to create microneedle vaccines that avoid the need for refrigeration. Altogether, this suggests that microneedle vaccines should be able to be stockpiled under much less costly conditions and possibly at a greater number of locations.

Distribution should also be facilitated by the small size and expected thermal stability of solidstate microneedle vaccines. The U.S. Department of Health and Human Services has a goal of distributing drugs and vaccines via the postal service in a pandemic or other urgent scenario to every home in the United States within 12 hours [26,27]. Realizing this vision would be simplified by using a small, flat, light microneedle patch that can easily fit inside a standard envelope or small package.

Finally, microneedles may reduce the risks associated with disposal of standard hypodermic needles because inadvertent microneedle insertion is difficult and dissolving polymer microneedles leave behind no sharp waste. 


\subsection{Vaccine patch manufacturing}

A variety of vaccine delivery systems are being studied [66,91], but many are expected to be much more expensive than the conventional needle and syringe, due to the cost of the delivery system itself and the added complexity of distributing and administering the vaccine.

Microneedle devices are expected to have a cost similar to conventional needle and syringe and to have significant cost savings associated with distribution, due largely to the small size of microneedle; administration, due largely to the expected reduced need for trained personnel; and vaccine antigen, due largely to the expectation that intracutaneous delivery can be dose sparing.

Different microneedle designs achieve their cost effectiveness through fabrication in different ways. Solid metal microneedles are typically fabricated by cutting metal sheets into the desired needle geometries using either chemical etchants or lasers [29,47,54]. Vaccine coatings are then applied by dip-coating processes with safe, low-cost excipients. Polymer microneedles have been fabricated using molding methods, in which the micromolds are typically prepared in a microelectronics cleanroom environment and then repeatly reused to mold microneedles in a conventional manufacturing environment by adapting in situ polymerization, solvent casting and injection molding/embossing techniques $[60,68,84]$. Hollow microneedles have been fabricated by direct etching in the cleanroom, reproduction using electroplating onto micromolds, or adaptation of conventional hypodermic needle manufacturing methods [28, $56,59,82,85]$. All of these methods lend themselves to scale up for mass production at low cost, where processing is generally the dominant cost, because the small size of microneedles means that material costs are much less. In addition, because microneedle delivery is expected to require less vaccine per dose, there should be additional savings on the cost of antigen.

\section{Conclusions}

Microneedles provide a number of advantages and opportunities to deliver vaccines more effectively, especially in the event of a pandemic influenza outbreak. Intracutaneous delivery has been shown in a number of studies not only to be effective, but to dramatically reduce the amount of antigen needed in a dose-sparing manner. Microneedles have yielded similar findings with a number of different antigens, including vaccines against seasonal influenza in Phase II clinical trials. Because of their small size and inert materials of construction, microneedles have not raised safety concerns. Overall, it appears likely that microneedles can provide a safe and effective method to deliver influenza vaccine.

In addition, microneedles offer other advantages compared to conventional needle-and-syringe and other delivery methods that may also be safe and effective. For example, the patch-based format of many microneedle designs should facilitate simple vaccine administration and possibly self administration by patients themselves. The small size of microneedle systems should also facilitate storage and rapid distribution to central locations or even to individual households by the postal service. Combined with the expected low cost of manufacturing, these attributes suggests that microneedles are an attractive platform for vaccine delivery and can play an important role in the medical response to an influenza pandemic.

\section{Acknowledgments}

This work was supported in part by the Georgia Research Alliance and National Institutes of Health grants 1U01AI074579 and 1R01EB006369. Mark Prausnitz is the Emerson-Lewis Faculty Fellow and is a member of the Center for Drug Design, Development and Delivery and the Institute for Bioengineering and Biosciences at the Georgia Institute of Technology. 


\section{References}

1. Physicians' Desk Reference. Montvale, NJ: Thomson PDR; 2007.

2. Progress toward interruption of wild poliovirus transmission--worldwide, January 2006-May 2007. MMWR Morb Mortal Wkly Rep 2007;56:682-685. [PubMed: 17625496]

3. Adams D, Quayum M, Worthington T, Lambert P, Elliott T. Evaluation of a $2 \%$ chlorhexidine gluconate in 70\% isopropyl alcohol skin disinfectant. J Hosp Infect 2005;61:287-290. [PubMed: 16221509]

4. Alarcon JB, Hartley AW, Harvey NG, Mikszta JA. Preclinical evaluation of microneedle technology for intradermal delivery of influenza vaccines. Clin Vaccine Immunol 2007;14:375-381. [PubMed: 17329444]

5. Andersen KE, Boman A, Volund A, Wahlberg JE. Induction of formaldehyde contact sensitivity: dose response relationship in the guinea pig maximization test. Acta Derm Venereol 1985;65:472-478. [PubMed: 2420109]

6. Atkinson WL, Pickering LK, Schwartz B, Weniger BG, Iskander JK, Watson JC. General recommendations on immunization. Recommendations of the Advisory Committee on Immunization Practices (ACIP) and the American Academy of Family Physicians (AAFP). MMWR Recomm Rep 2002;51:1-35. [PubMed: 11848294]

7. Auewarakul P, Kositanont U, Sornsathapornkul P, Tothong P, Kanyok R, Thongcharoen P. Antibody responses after dose-sparing intradermal influenza vaccination. Vaccine 2007;25:659-663. [PubMed: 17011678]

8. Barker, JH.; Ryan, TJ. Skin microcirculation. In: Barker, JH.; Anderson, GL.; Menger, MD., editors. Clinically Applied Microcirculation Research. Boca Raton: CRC Press; 1995. p. 315-338.

9. Belshe RB, Newman FK, Cannon J, Duane C, Treanor J, Van Hoecke C, Howe BJ, Dubin G. Serum antibody responses after intradermal vaccination against influenza. N Engl J Med 2004;351:22862294. [PubMed: 15525713]

10. Belshe RB, Newman FK, Wilkins K, Graham IL, Babusis E, Ewell M, Frey SE. Comparative immunogenicity of trivalent influenza vaccine administered by intradermal or intramuscular route in healthy adults. Vaccine 2007;25:6755-6763. [PubMed: 17692438]

11. Birchall J, Coulman S, Pearton M, Allender C, Brain K, Anstey A, Gateley C, Wilke N, Morrissey A. Cutaneous DNA delivery and gene expression in ex vivo human skin explants via wet-etch microfabricated micro-needles. J Drug Target 2005;13:415-421. [PubMed: 16308210]

12. Birchall JC. Microneedle array technology: the time is right but is the science ready? Expert Rev Med Devices 2006;3:1-4. [PubMed: 16359245]

13. Bronaugh, RL.; Maibach, HI. Percutaneous Absorption. New York: Marcel Dekker; 2005.

14. Brown H, Kasel JA, Freeman DM, Moise LD, Grose NP, Couch RB. The immunizing effect of influenza A/New Jersey/76 (Hsw1N1) virus vaccine administered intradermally and intramuscularly to adults. J Infect Dis 1977;136 Suppl:S466-S471. [PubMed: 606768]

15. Chabri F, Bouris K, Jones T, Barrow D, Hann A, Allender C, Brain K, Birchall J. Microfabricated silicon microneedles for nonviral cutaneous gene delivery. Br J Dermatol 2004;150:869-877. [PubMed: 15149498]

16. Chiu SS, Peiris JS, Chan KH, Wong WH, Lau YL. Immunogenicity and safety of intradermal influenza immunization at a reduced dose in healthy children. Pediatrics 2007;119:1076-1082. [PubMed: 17545373]

17. Cormier, M.; Daddona, PE. Macroflux technology for transdermal delivery of therapeutic proteins and vaccines. In: Rathbone, MJ.; Hadgraft, J.; Roberts, MS., editors. Modified-Release Drug Delivery Technology. New York: Marcel Dekker; 2003. p. 589-598.

18. Cormier M, Johnson B, Ameri M, Nyam K, Libiran L, Zhang DD, Daddona P. Transdermal delivery of desmopressin using a coated microneedle array patch system. J Control Release 2004;97:503511. [PubMed: 15212882]

19. Coulman S, Allender C, Birchall J. Microneedles and other physical methods for overcoming the stratum corneum barrier for cutaneous gene therapy. Crit Rev Ther Drug Carrier Syst 2006;23:205258. [PubMed: 17206925] 
20. Coulman SA, Barrow D, Anstey A, Gateley C, Morrissey A, Willke N, Allender C, Brain K, Birchall JC. Minimally invasive delivery of macromolecules and plasmid DNA via microneedles. Current Drug Delivery 2006;3:65-75. [PubMed: 16472095]

21. Davis SP, Landis BJ, Adams ZH, Allen MG, Prausnitz MR. Insertion of microneedles into skin: measurement and prediction of insertion force and needle fracture force. J. Biomech 2004;37:11551163. [PubMed: 15212920]

22. Davis SP, Martanto W, Allen MG, Prausnitz MR. Transdermal insulin delivery to diabetic rats through microneedles. IEEE Transactions on Biomedical Engineering 2005;52:909-915. [PubMed: 15887540]

23. Dean CH, Alarcon JB, Waterston AM, Draper K, Early R, Guirakhoo F, Monath TP, Mikszta JA. Cutaneous delivery of a live, attenuated chimeric flavivirus vaccine against Japanese encephalitis (ChimeriVax)-JE) in non-human primates. Hum Vaccin 2005;1:106-111. [PubMed: 17012854]

24. Diaz-Ortega JL, Forsey T, Clements CJ, Milstien J. The relationship between dose and response of standard measles vaccines. Biologicals 1994;22:35-44. [PubMed: 8068312]

25. Ellner PD. Smallpox: gone but not forgotten. Infection 1998;26:263-269. [PubMed: 9795781]

26. Fauci AS. Pandemic influenza threat and preparedness. Emerg Infect Dis 2006;12:73-77. [PubMed: 16494721]

27. Freking, K. HHS May Use Mail to Deliver Emergency Meds, Health News. 2005 [Accessed October 30, 2007]. (http://www.health-news.org/breaking/2885/hhs-may-use-mail-to-deliver-emergency-meds.html)

28. Gardeniers JGE, Luttge R, Berenschot JW, de Boer MJ, Yeshurun Y, Hefetz M, van 't Oever R, van den Berg A. Silicon micromachined hollow microneedles for transdermal liquid transport. J MEMS 2003;6:855-862.

29. Gill HS, Prausnitz MR. Coated microneedles for transdermal delivery. J Control Release 2007;117:227-237. [PubMed: 17169459]

30. Gill HS, Prausnitz MR. Coating formulations for microneedles. Pharm Res. (in press).

31. Gill HS, Prausnitz MR. Pocketed microneedles for drug delivery to the skin. J Phys Chem Solids. (in press).

32. Gill HS, Prausnitz MR. Effect of microneedle design on pain in human subjects. (submitted).

33. Gostin LO. Medical countermeasures for pandemic influenza: ethics and the law. Jama 2006;295:554556. [PubMed: 16449621]

34. Halperin W, Weiss WI, Altman R, Diamond MA, Black KJ, Iaci AW, Black HC, Goldfield M. A comparison of the intradermal and subcutaneous routes of influenza vaccination with A/New Jersey/ 76 (swine flu) and A/Victoria/75: report of a study and review of the literature. Am J Public Health 1979;69:1247-1251. [PubMed: 507256]

35. Henry S, McAllister DV, Allen MG, Prausnitz MR. Microfabricated microneedles: a novel approach to transdermal drug delivery. J Pharm Sci 1998;87:922-925. [PubMed: 9687334]

36. Herbert FA, Larke RP, Markstad EL. Comparison of responses to influenza A/New Jersey/76-A/ Victoria/75 virus vaccine administered intradermally or subcutaneously to adults with chronic respiratory disease. J Infect Dis 1979;140:234-238. [PubMed: 479641]

37. Hooper JW, Golden JW, Ferro AM, King AD. Smallpox DNA vaccine delivered by novel skin electroporation device protects mice against intranasal poxvirus challenge. Vaccine 2007;25:18141823. [PubMed: 17240007]

38. Huang CM. Topical vaccination: the skin as a unique portal to adaptive immune responses. Semin Immunopathol 2007;29:71-80. [PubMed: 17621956]

39. Ito Y, Hagiwara E, Saeki A, Sugioka N, Takada K. Feasibility of microneedles for percutaneous absorption of insulin. Eur J Pharm Sci 2006;29:82-88. [PubMed: 16828268]

40. Ito Y, Yoshimitsu J, Shiroyama K, Sugioka N, Takada K. Self-dissolving microneedles for the percutaneous absorption of EPO in mice. J Drug Target 2006;14:255-261. [PubMed: 16882545]

41. Kaushik S, Hord AH, Denson DD, McAllister DV, Smitra S, Allen MG, Prausnitz MR. Lack of pain associated with microfabricated microneedles. Anesth. Analg 2001;92:502-504. [PubMed: 11159258] 
42. Kenney RT, Frech SA, Muenz LR, Villar CP, Glenn GM. Dose sparing with intradermal injection of influenza vaccine. N Engl J Med 2004;351:2295-2301. [PubMed: 15525714]

43. La Montagne JR, Fauci AS. Intradermal influenza vaccination--can less be more? N Engl J Med 2004;351:2330-2332. [PubMed: 15525715]

44. Larregina AT, Falo LD Jr. Changing paradigms in cutaneous immunology: adapting with dendritic cells. J Invest Dermatol 2005;124:1-12. [PubMed: 15654947]

45. Laurent PE, Bonnet S, Alchas P, Regolini P, Mikszta JA, Pettis R, Harvey NG. Evaluation of the clinical performance of a new intradermal vaccine administration technique and associated delivery system. Vaccine 2007;25:8833-8842. [PubMed: 18023942]

46. Lambert P-H, Laurent PE. Intradermal vaccine delivery: will new delivery systems transform vaccine administration? Vaccine. (in press).

47. Lee J-W, Park J-H, Prausnitz MR. Dissolving microneedles for transdermal drug delivery. Biomaterials. (in press).

48. Lin W, Cormier M, Samiee A, Griffin A, Johnson B, Teng C, Hardee GE, Daddona P. Transdermal delivery of antisense oligonucleotides with microprojection patch (Macroflux) technology. Pharm. Res 2001;18:1789-1793. [PubMed: 11785702]

49. Lowry PW, Sabella C, Koropchak CM, Watson BN, Thackray HM, Abbruzzi GM, Arvin AM. Investigation of the pathogenesis of varicella-zoster virus infection in guinea pigs by using polymerase chain reaction. J Infect Dis 1993;167:78-83. [PubMed: 8380293]

50. Maa, Y-F.; Sellers, S.; Matriano, J. Ramdas A Apparatus and method for transdermal delivery of influenza vaccine. United States Patent Application. 20050220854.

51. Martanto W, Davis S, Holiday N, Wang J, Gill H, Prausnitz M. Transdermal delivery of insulin using microneedles in vivo. Pharm. Res 2004;21:947-952. [PubMed: 15212158]

52. Martanto W, Moore JS, Couse T, Prausnitz MR. Mechanism of fluid infusion during microneedle insertion and retraction. J Control Release 2006;112:357-361. [PubMed: 16626836]

53. Martanto W, Moore JS, Kashlan O, Kamath R, Wang PM, O'Neal JM, Prausnitz MR. Microinfusion using hollow microneedles. Pharm Res 2006;23:104-113. [PubMed: 16308670]

54. Matriano JA, Cormier M, Johnson J, Young WA, Buttery M, Nyam K, Daddona PE. Macroflux microprojection array patch technology: a new and efficient approach for intracutaneous immunization. Pharm. Res 2002;19:63-70. [PubMed: 11837701]

55. McAllister DV, Allen MG, Prausnitz MR. Microfabricated microneedles for gene and drug delivery. Annu. Rev. Biomed. Eng 2000;2:289-313. [PubMed: 11701514]

56. McAllister DV, Wang PM, Davis SP, Park J-H, Canatella PJ, Allen MG, Prausnitz MR. Microfabricated needles for transdermal delivery of macromolecules and nanoparticles: fabrication methods and transport studies. Proc Natl Acad Sci U S A 2003;100:13755-13760. [PubMed: 14623977]

57. Mikszta JA, Alarcon JB, Brittingham JM, Sutter DE, Pettis RJ, Harvey NG. Improved genetic immunization via micromechanical disruption of skin-barrier function and targeted epidermal delivery. Nat. Med 2002;8:415-419. [PubMed: 11927950]

58. Mikszta JA, Dekker JP 3rd, Harvey NG, Dean CH, Brittingham JM, Huang J, Sullivan VJ, Dyas B, Roy CJ, Ulrich RG. Microneedle-based intradermal delivery of the anthrax recombinant protective antigen vaccine. Infect Immun 2006;74:6806-6810. [PubMed: 17030580]

59. Mikszta JA, Sullivan VJ, Dean C, Waterston AM, Alarcon JB, Dekker JP 3rd, Brittingham JM, Huang J, Hwang CR, Ferriter M, Jiang G, Mar K, Saikh KU, Stiles BG, Roy CJ, Ulrich RG, Harvey NG. Protective immunization against inhalational anthrax: a comparison of minimally invasive delivery platforms. J Infect Dis 2005;191:278-288. [PubMed: 15609239]

60. Miyano T, Tobinaga Y, Kanno T, Matsuzaki Y, Takeda H, Wakui M, Hanada K. Sugar micro needles as transdermic drug delivery system. Biomed Microdevices 2005;7:185-188. [PubMed: 16133805]

61. Miyauchi H, Horio T. A new animal model for contact dermatitis: the hairless guinea pig. J Dermatol 1992;19:140-145. [PubMed: 1640019]

62. Monath TP. Yellow fever vaccine. Expert Rev Vaccines 2005;4:553-574. [PubMed: 16117712]

63. Monath TP, Guirakhoo F, Nichols R, Yoksan S, Schrader R, Murphy C, Blum P, Woodward S, McCarthy K, Mathis D, Johnson C, Bedford P. Chimeric live, attenuated vaccine against Japanese encephalitis (ChimeriVax-JE): phase 2 clinical trials for safety and immunogenicity, effect of vaccine 
dose and schedule, and memory response to challenge with inactivated Japanese encephalitis antigen. J Infect Dis 2003;188:1213-1230. [PubMed: 14551893]

64. Nestle FO, Nickoloff BJ. Deepening our understanding of immune sentinels in the skin. J Clin Invest 2007;117:2382-2385. [PubMed: 17786233]

65. Nordquist L, Roxhed N, Griss P, Stemme G. Novel microneedle patches for active insulin delivery are efficient in maintaining glycaemic control: an initial comparison with subcutaneous administration. Pharm Res 2007;24:1381-1388. [PubMed: 17387600]

66. O'Hagan DT, Rappuoli R. Novel approaches to vaccine delivery. Pharm Res 2004;21:1519-1530. [PubMed: 15497674]

67. Park J-H, Allen MG, Prausnitz MR. Biodegradable polymer microneedles: fabrication, mechanics and transdermal drug delivery. J. Control. Release 2005;104:51-66. [PubMed: 15866334]

68. Park JH, Allen MG, Prausnitz MR. Polymer microneedles for controlled-release drug delivery. Pharm Res 2006;23:1008-1019. [PubMed: 16715391]

69. Pearton M, Allender C, Brain K, Anstey A, Gateley C, Wilke N, Morrissey A, Birchall J. Gene delivery to the epidermal cells of human skin explants using microfabricated microneedles and hydrogel formulations. Pharm Res. 2007

70. Pickup DJ. Understanding orthopoxvirus interference with host immune responses to inform novel vaccine design. Expert Rev Vaccines 2007;6:87-95. [PubMed: 17280481]

71. Prausnitz, M. Assessment of microneedles for transdermal drug delivery. In: Bronaugh, R.; Maibach, H., editors. Absorption Percutaneous. New York: Marcel Dekker; 2005. p. 497-507.

72. Prausnitz, M.; Ackley, D.; Gyory, J. Microneedles for transdermal drug delivery. In: Rathbone, M.; Hadgraft, J.; Roberts, M., editors. Modified Release Drug Delivery Systems. New York: Marcel Dekker; 2003. p. 513-522.

73. Prausnitz, M.; Mikszta, J.; Raeder-Devens, J. Microneedles. In: Smith, E.; Maibach, H., editors. Percutaneous Penetration Enhancers. Boca Raton, FL: CRC Press; 2005. p. 239-255.

74. Prausnitz MR. Microneedles for transdermal drug delivery. Adv. Drug Deliv. Rev 2004;56:581-587. [PubMed: 15019747]

75. Prausnitz, MR.; Gill, HS.; Park, J-H. Microneedles for drug delivery. In: Rathbone, MJ.; Hadgraft, J.; Roberts, MS.; Lane, ME., editors. Modified Release Drug Delivery. New York: Informa Healthcare; (in press)

76. Prausnitz MR, Mitragotri S, Langer R. Current status and future potential of transdermal drug delivery. Nat Rev Drug Discov 2004;3:115-124. [PubMed: 15040576]

77. Reed ML, Lye W-K. Microsystems for drug and gene delivery. Proc IEEE 2004;92:56-75.

78. Roth RR, James WD. Microbiology of the skin: resident flora, ecology, infection. J Am Acad Dermatol 1989;20:367-390. [PubMed: 2645319]

79. Ruble DL, Elliott JJ, Waag DM, Jaax GP. A refined guinea pig model for evaluating delayed-type hypersensitivity reactions caused by Q fever vaccines. Lab Anim Sci 1994;44:608-612. [PubMed: 7898035]

80. Shirkhanzadeh M. Microneedles coated with porous calcium phosphate ceramics: effective vehicles for transdermal delivery of solid trehalose. J Mater Sci Mater Med 2005;16:37-45. [PubMed: 15754142]

81. Sivamani RK, Liepmann D, Maibach HI. Microneedles and transdermal applications. Expert Opin Drug Deliv 2007;4:19-25. [PubMed: 17184159]

82. Sivamani RK, Stoeber B, Wu GC, Zhai H, Liepmann D, Maibach H. Clinical microneedle injection of methyl nicotinate: stratum corneum penetration. Skin Res Technol 2005;11:152-156. [PubMed: 15807814]

83. Subbarao K, Murphy BR, Fauci AS. Development of effective vaccines against pandemic influenza. Immunity 2006;24:5-9. [PubMed: 16413916]

84. Sullivan SP, Murthy N, Prausnitz MR. Minimally invasive protein delivery with rapidly dissolving polymer microneedles. Adv. Mat. (in press).

85. Teo MA, Shearwood C, $\mathrm{Ng} \mathrm{KC,} \mathrm{Lu} \mathrm{J,} \mathrm{Moochhala} \mathrm{S.} \mathrm{In} \mathrm{vitro} \mathrm{and} \mathrm{in} \mathrm{vivo} \mathrm{characterization} \mathrm{of} \mathrm{MEMS}$ microneedles. Biomed Microdevices 2005;7:47-52. [PubMed: 15834520] 
86. Ulmer JB, Valley U, Rappuoli R. Vaccine manufacturing: challenges and solutions. Nat Biotechnol 2006;24:1377-1383. [PubMed: 17093488]

87. Verbaan FJ, Bal SM, van Berg den DJ, Groenink WH, Verpoorten H, Luttge R, Bouwstra JA. Assembled microneedle arrays enhance the transport of compounds varying over a large range of molecular weight across human dermatomed skin. J Control Release 2007;117:238-245. [PubMed: 17196697]

88. Wang P, Cornwell M, Prausnitz M. Minimally invasive extraction of dermal interstitial fluid for glucose monitoring using glass microneedles. Diabetes Technol Ther 2005;7:131-141. [PubMed: 15738711]

89. Wang PM, Cornwell M, Hill J, Prausnitz MR. Precise microinjection into skin using hollow microneedles. J Invest Dermatol 2006;126:1080-1087. [PubMed: 16484988]

90. Webby RJ, Webster RG. Are we ready for pandemic influenza? Science 2003;302:1519-1522. [PubMed: 14645836]

91. Weniger, BG.; Papania, M. Alternative vaccine delivery methods. In: Plotkn, S.; Orenstein, W.; Offit, P., editors. Vaccines. Philadelphia: Elsevier; (in press)

92. Widera G, Johnson J, Kim L, Libiran L, Nyam K, Daddona PE, Cormier M. Effect of delivery parameters on immunization to ovalbumin following intracutaneous administration by a coated microneedle array patch system. Vaccine 2006;24:1653-1664. [PubMed: 16246466]

93. Wiser I, Balicer RD, Cohen D. An update on smallpox vaccine candidates and their role in bioterrorism related vaccination strategies. Vaccine 2007;25:976-984. [PubMed: 17074424]

94. Woodward, DF.; Nieves, AL.; Williams, LS.; Spada, CS.; Hawley, SB.; Duenes, JL. A new hairless strain of guinea pig: characterization of the cutaneous morphology and pharmacology. In: Maibach, HI.; Lowe, NJ., editors. Models in dermatology. Basel: Karger; 1989. p. 71-78.

95. Wu XM, Todo H, Sugibayashi K. Effects of pretreatment of needle puncture and sandpaper abrasion on the in vitro skin permeation of fluorescein isothiocyanate (FITC)-dextran. Int J Pharm 2006;316:102-108. [PubMed: 16597490]

96. Wu XM, Todo H, Sugibayashi K. Enhancement of skin permeation of high molecular compounds by a combination of microneedle pretreatment and iontophoresis. J Control Release 2007;118:189-195. [PubMed: 17270306]

97. Xie Y, Xu B, Gao Y. Controlled transdermal delivery of model drug compounds by MEMS microneedle array. Nanomedicine 2005;1:184-190. [PubMed: 17292077]

98. Yang M, Zahn JD. Microneedle insertion force reduction using vibratory actuation. Biomed Microdevices 2004;6:177-182. [PubMed: 15377826] 

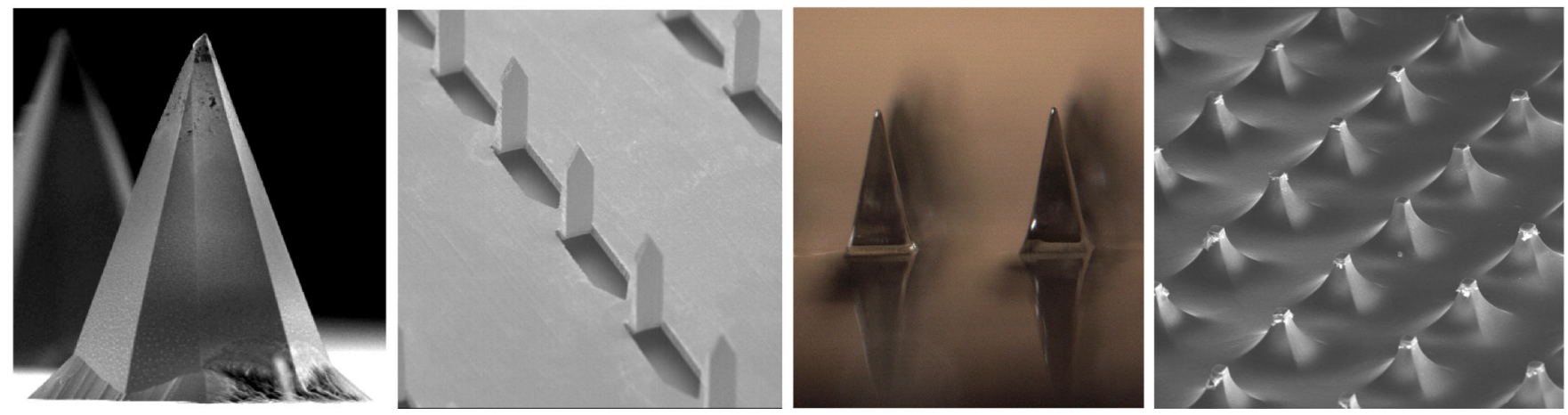

Fig. 1.

Solid microneedles used either to pierce or to scrape microscopic holes in the skin. Shown from left to right: platinum-coated silicon microneedle measuring $170 \mu \mathrm{m}$ in height (image courtesy of James Birchall, Cardiff University); metal microneedles measuring $700 \mu \mathrm{m}$ in height (image courtesy of Harvinder Gill, Georgia Institute of Technology); dissolving polymer microneedles measuring $650 \mu \mathrm{m}$ in height (image courtesy of Sean Sullivan, Georgia Institute of Technology); blunt-tip polymer microneedles measuring $150 \mu \mathrm{m}$ in height to scrape the skin (image courtesy of John Mikszta, BD Technologies). 

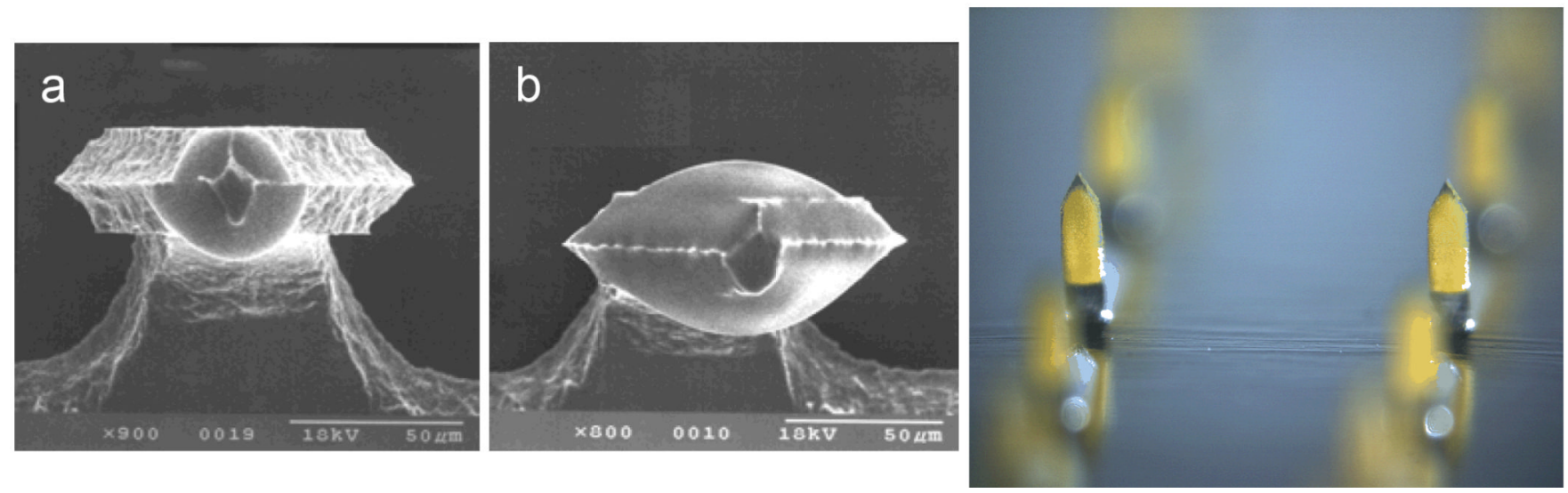

Fig. 2.

Solid microneedles coated with model compounds. Shown from left to right: metal microneedles measuring $225 \mu \mathrm{m}$ in height coated with approximately (a) $1.4 \mathrm{ng}$ and (b) $19 \mathrm{ng}$ of ovalbumin and viewed from above, looking from their tips down their shafts (images courtesy of Michel Cormier, Alza Corporation); metal microneedles measuring $700 \mu \mathrm{m}$ in height each coated with approximately $2 \mu \mathrm{g}$ vitamin B (image courtesy of Harvinder Gill, Georgia Institute of Technology). 

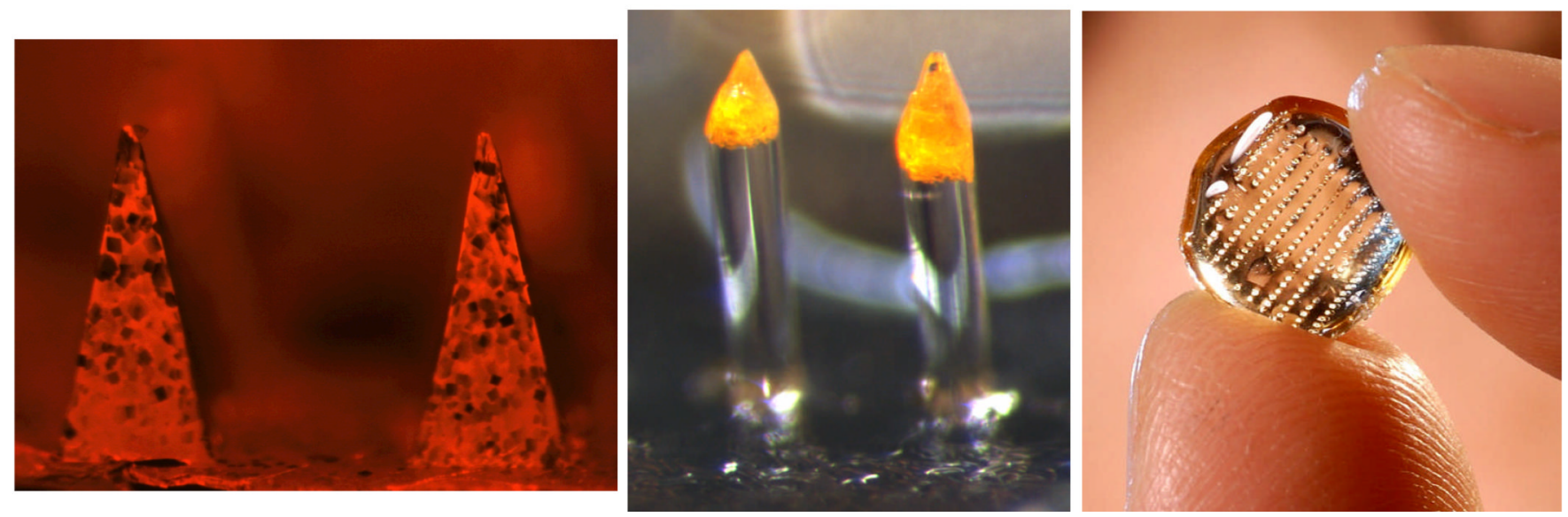

Fig. 3.

Dissolving or degrading polymer microneedles that encapsulate model compounds. Shown from left to right: dissolving polymer microneedles measuring $600 \mu \mathrm{m}$ in height encapsulating sulforhodamine (image courtesy of Jeong Woo Lee, Georgia Institute of Technology); biodegradable polymer microneedles measuring $600 \mu \mathrm{m}$ in height encapsulating calcein (image courtesy of Jung-Hwan Park, Georgia Institute of Technology); array of biodegradable polymer microneedles held between two fingers (image courtesy of Gary Meek, Georgia Institute of Technology). 

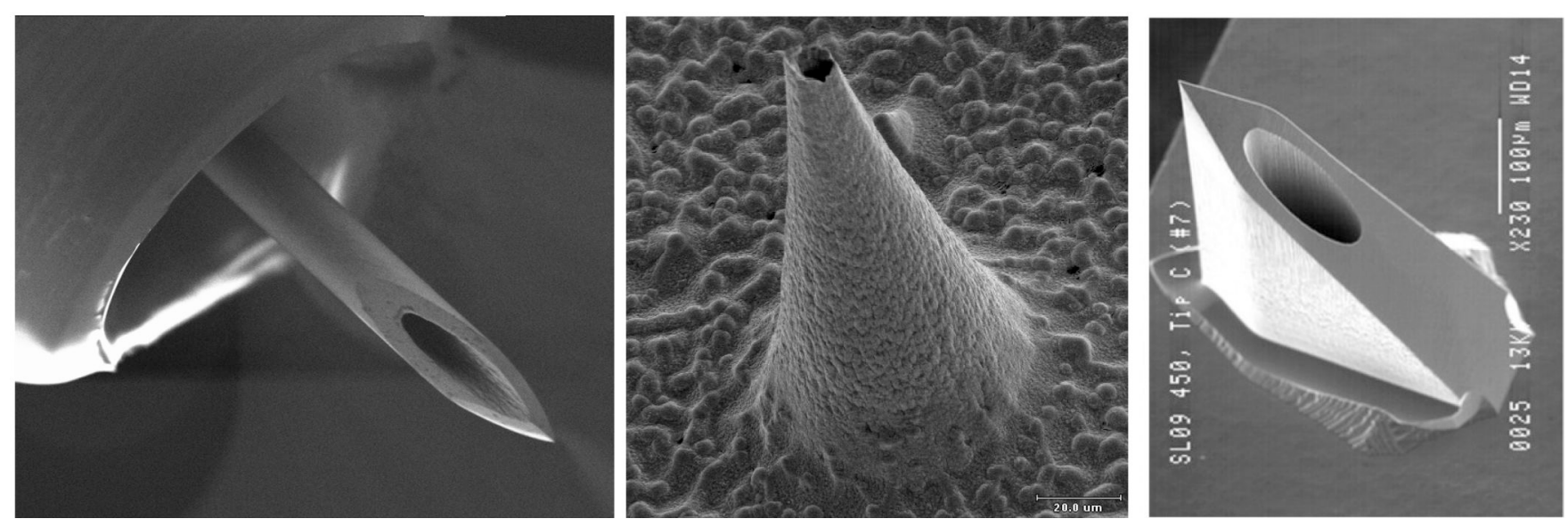

Fig. 4.

Hollow microneedles for injection into the skin. Shown from left to right: metal hypodermic needle protruding $1.5 \mathrm{~mm}$ from a specially designed hub for intradermal delivery (image courtesy of John Mikszta, BD Technologies); metal microneedle measuring $150 \mu \mathrm{m}$ in height (image courtesy of Devin McAllister, Georgia Institute of Technology); silicon microneedle measuring $200 \mu \mathrm{m}$ in height (image courtesy of Yotam Levin, NanoPass Technologies). 
A

C

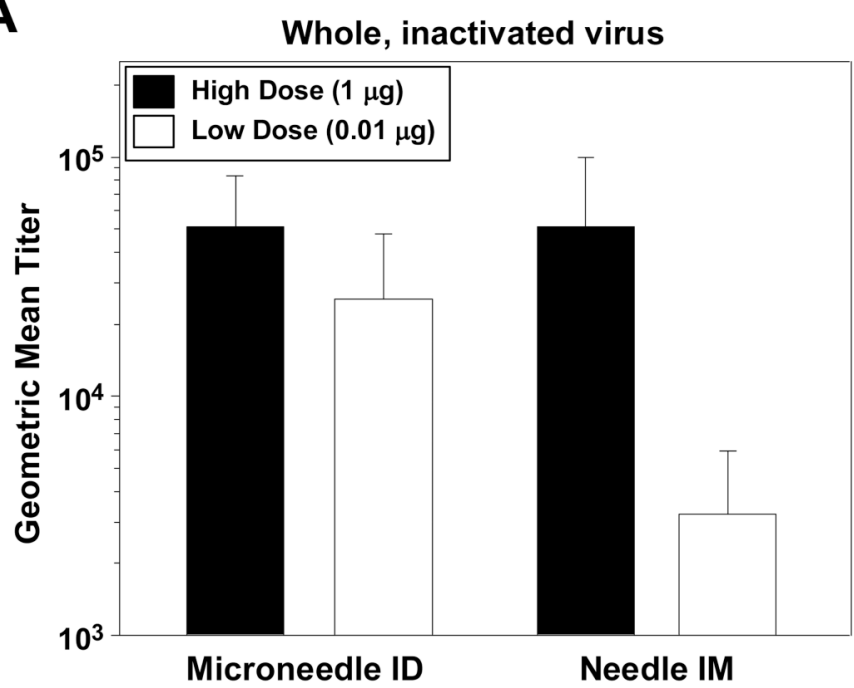

B
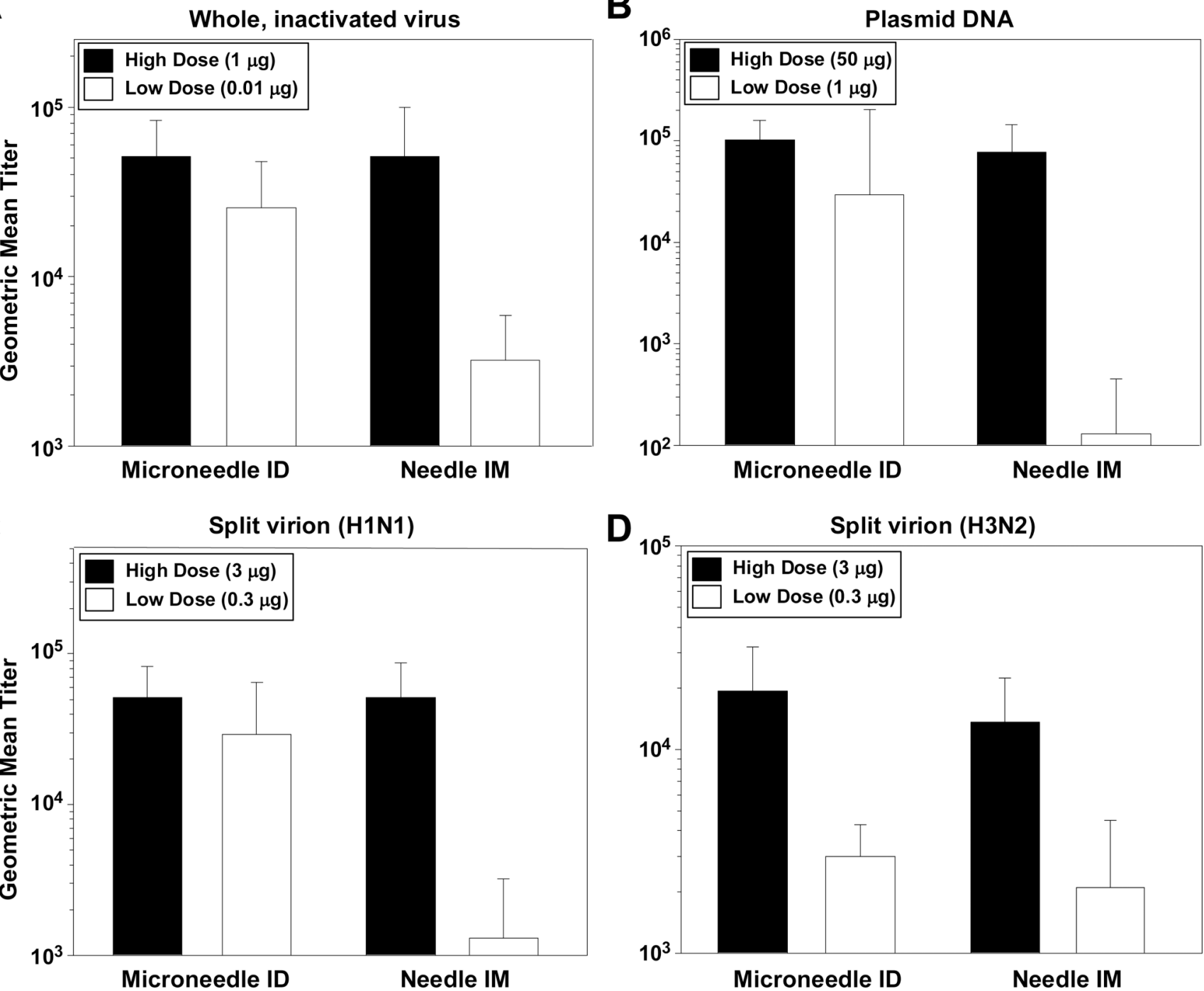

D

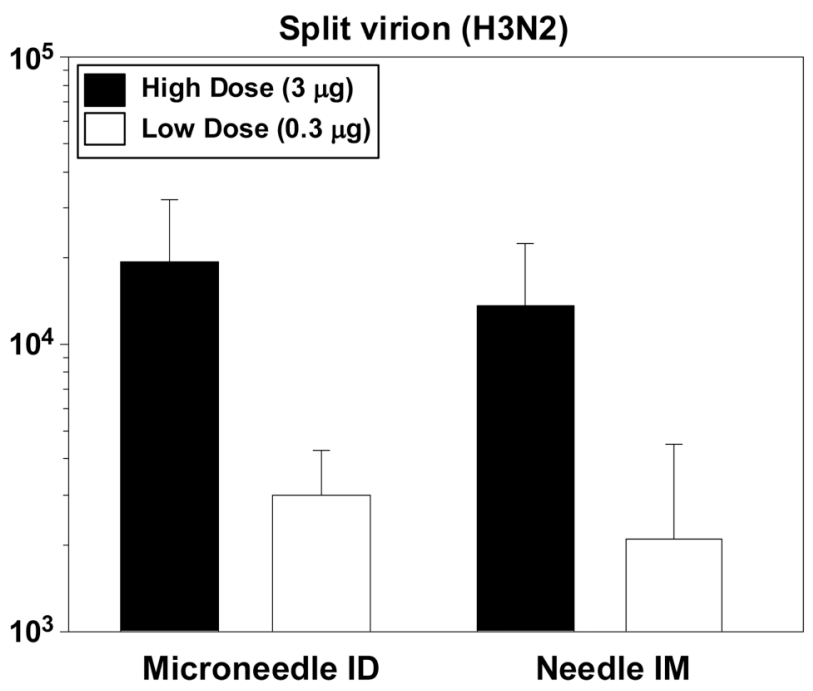

Fig. 5.

Antibody response to influenza vaccines in rats. Data represent a subset of those originally reported in reference [4]. (A) Antibody response to whole, inactivated influenza virus following immunization with either a high dose or low dose of vaccine. Data represent day 56 ELISA titers following immunization on day 0 , day 21 and day 42. (B) Antibody response to influenza virus following immunization with either a high dose or low dose of plasmid DNA encoding influenza virus hemagglutinin. Data represent day 56 ELISA titers following immunization on day 0 , day 21 and day 42. (C) Antibody response to the H1N1 strain of influenza virus following immunization with either a high dose or low dose of trivalent, split virion vaccine. Data represent day 21 ELISA titers following a single immunization. (D) Antibody response to the H3N2 strain of influenza virus following immunization with either a high dose or low dose of trivalent, split virion vaccine. Data represent day 21 ELISA titers following a single immunization. 


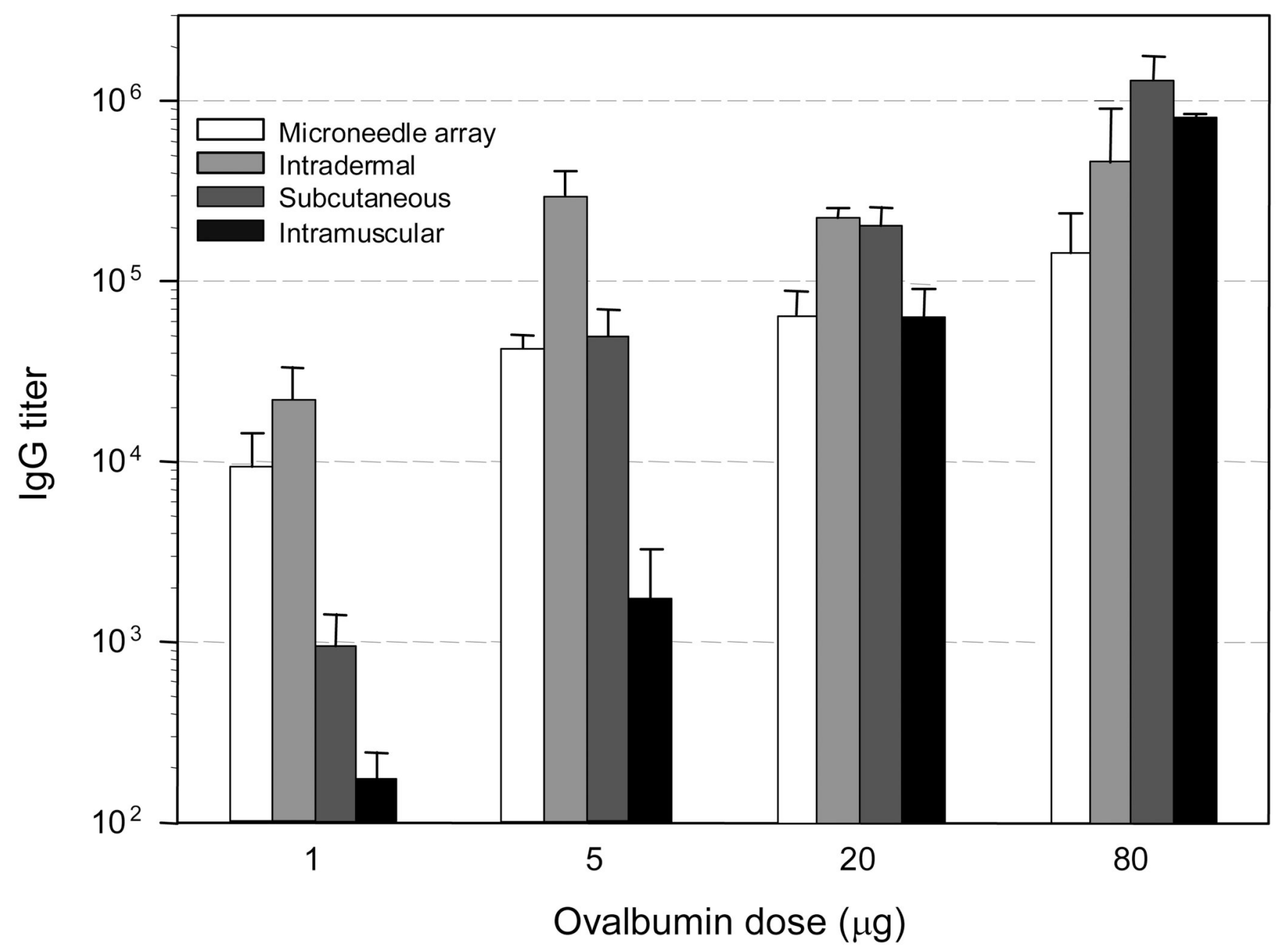

Fig. 6.

Anti-ovalbumin antibody response to ovalbumin immunization in hairless guinea pigs. Each animal received a primary immunization followed by a secondary immunization (booster) 4 weeks later with the same ovalbumin dose [54]. The routes of administration were intracutaneous using coated microneedle arrays, ID, SC, and IM injection. The serum samples were collected 1 week after the booster immunization and evaluated for the presence of antiovalbumin IgG antibodies by ELISA. The results are expressed as end-point antibody titers relative to non-immunized control sera. 


\section{Table 1}

Viremia and neutralizing antibody response in non-human primates following immunization with ChimeriVax ${ }^{\mathrm{TM}}$ JE. Data represent a subset of those originally reported in reference [23].

\begin{tabular}{|c|c|c|c|c|}
\hline \multirow[b]{2}{*}{ Delivery } & \multicolumn{2}{|c|}{ Viremia } & \multicolumn{2}{|l|}{ Nabs } \\
\hline & \# Responders & Duration & \# Responders & Titer \\
\hline Needle & $1 / 3$ & 3 days & $3 / 3$ & 1,067 \\
\hline Hollow microneedle & $3 / 3$ & 2-4 days & $3 / 3$ & 7,253 \\
\hline $\begin{array}{l}\text { Solid Microneedle } \\
\text { (pre-abrasion) }\end{array}$ & $1 / 3$ & 7 days & $1 / 3$ & 3,467 \\
\hline $\begin{array}{l}\text { Solid Microneedle } \\
\text { (abrasion through vaccine) }\end{array}$ & $3 / 3$ & 5-7 days & $3 / 3$ & 4,320 \\
\hline
\end{tabular}

